\title{
Modelling and Dynamic Simulation of Cyclically Operated Pulverized Coal-Fired Power Plant
}

\author{
Juha Kuronen Miika Hotti Sami Tuuri \\ Fortum Power and Heat Oy, Espoo, Finland, \{juha.kuronen, miika.hotti, sami.tuuri\}@fortum.com
}

\begin{abstract}
Pulverized coal-fired power plants are increasingly operated cyclically for the compensation of fluctuating load in the electric grid caused by intermittent production of wind and solar power plants. Dynamic simulation is a powerful tool for investigating the transient behavior of a power plant that is operated cyclically. New solutions, e.g. process changes and control strategies can be tested with a computer-aided dynamic simulation software. This paper introduces a model and dynamic model validation of a commercial pulverized coal-fired power plant that is used in grid load compensation. The model is developed using dynamic simulation software Apros, and it includes all the main processes and control loops of the plant, but also some significant simplifications have been made compared to the real plant process. The model is validated against measurement data from the plant. Simulated dynamic validation cases include typical load changes that are used in grid load compensation. The model can be used for further investigations regarding flexibility and controllability of the plant.
\end{abstract}

Keywords: modelling, dynamic simulation, cyclic operation, pulverized coal-fired power plant, validation

\section{Introduction}

The production of renewable energy, especially wind and solar power, has expanded in the past few years in Europe due to growing concern about the climate change, emission restrictions on the energy markets and renewable energy subsidies. The load level of solar and wind power plants depends strongly on weather conditions which vary depending on the season and daytime. The intermittent renewable energy production leads to fluctuating load in the electric grid, and to balance the grid load some power plants are forced to compensate the load fluctuations by continuously controlling the power output of the plant. This operation mode is called cycling. In Central Europe conventional steam power plants, typically pulverized coal-fired units, are participating in the compensation. Traditionally large coal-fired units have been designed for base load operation, but due to increased renewable energy production base load plants are more and more operated in varying load levels. This sets new challenges for the flexibility and controllability of these plants.

These challenges can be divided into three categories. Firstly faster load transients between operational points as well as faster and more flexible start-up and shutdown processes are needed. Secondly the plant needs to be operated on broader range and the technical minimal load limit has to be re-evaluated. Thirdly the thermoeconomical optimization of the plant within the whole operational range need to be done, since the operation in full load is reduced. (Starkloff et al., 2015) In addition the rates of load transients, start-ups and shutdowns are limited by thermo-mechanical stress in boiler and turbine components. Uncontrollable stress reduces significantly the residual life of stress-prone plant components.

In order to respond to the load transient, flexibility, and thermo-economical optimization challenges, development and re-engineering work is typically needed in plants that are not designed for cyclic operation. This work may result e.g. in boiler heat surface constructional changes, burner upgrades or control strategy changes. New solutions can be easily tested with a computer-aided dynamic simulation tool. Hence modelling and dynamic simulation of pulverized coal-fired plants are increasingly important, and this topic has been covered in several recently published papers, e.g. (Starkloff et al., 2015; Richter et al., 2015; Krüger et al., 2015). This paper presents a dynamic simulation model of a commercial $750 \mathrm{MWe}$ pulverized coal-fired power plant that is operated both in base load and cyclic operation mode. The model is validated against operational plant data during typical load changes of the plant.

It is always necessary to know the purpose of the model and the accuracy needed from the model. In this work the main purpose is to simulate load-varying operation of the plant. For this purpose the main process sections and control loops of the plant are included in the model. Water and steam temperatures, pressures and mass flows in the boiler should equate with the real process, so that the load change transients can be simulated accurately. Therefore the boiler section must be modelled carefully. Since a development of an exact plant simulator was not the aim of this work, the model 


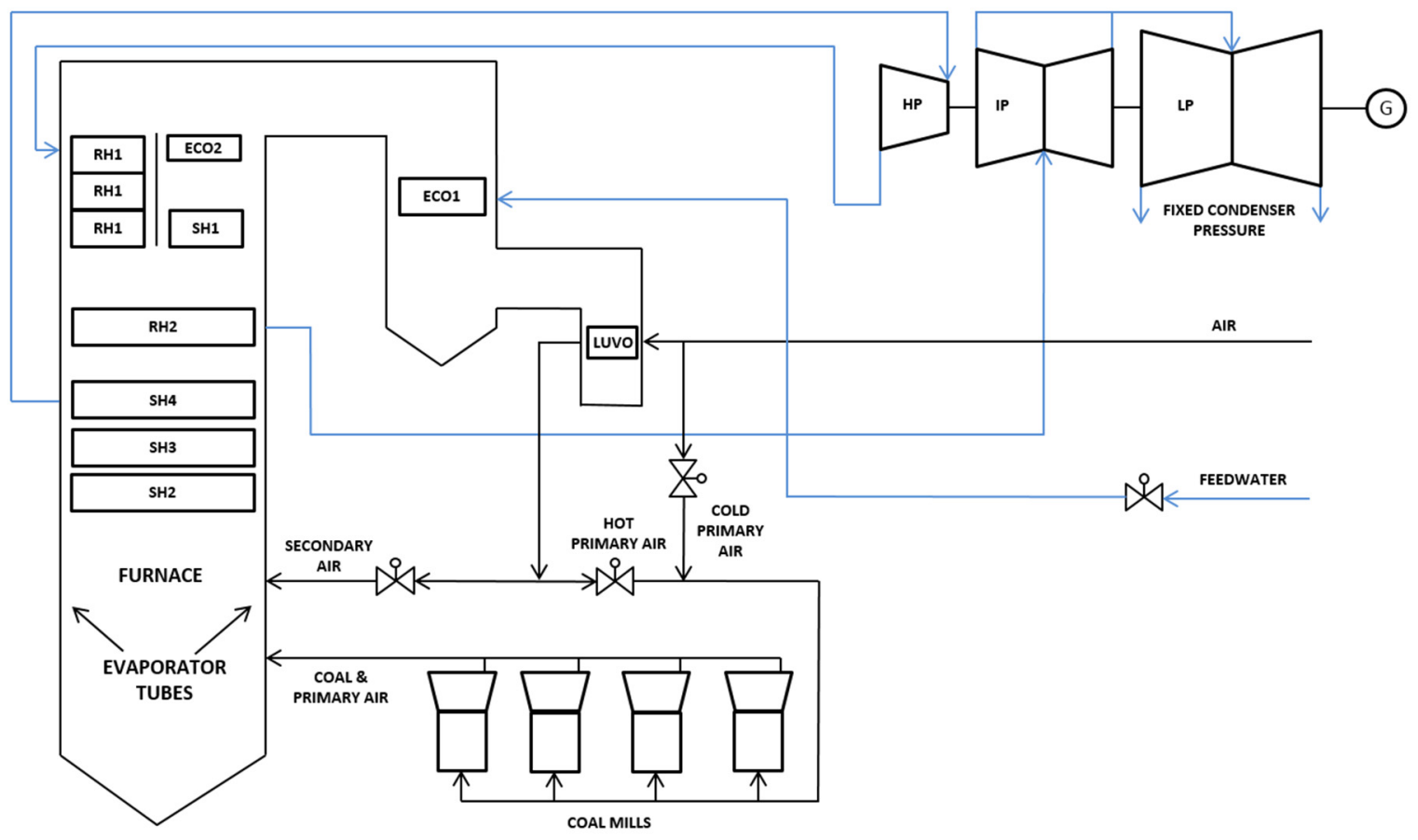

Figure 1. Schematic diagram of the plant model.

was adapted to the specific needs of the simulation experiments. In other words the process and control system models include considered simplifications compared to the real plant. For example feedwater section, including feedwater tank, pumps and preheaters, is not included in the model. The power plant process and control system were modelled in dynamic simulation software Apros.

The paper is structured as follows. After the introduction the simulation software Apros is introduced briefly in Section 2. The plant model is presented in Section 3. The validation results are discussed in Section 4 and the conclusions are given in Section 5.

\section{Simulation Environment}

Dynamic simulation software Apros was utilized for the modelling and simulation of the reference plant. Apros is a multifunctional software for full-scale modelling and dynamic simulation of power plants and industrial processes. Apros is the result of a quarter century's development work by VTT (Technical Research Centre of Finland) in co-operation with Fortum. It is used by multiple power plant operators, engineering companies, research institutes, safety authorities and universities all over the world.

Apros combines accurate physical process modelling with automation modelling. With Apros it is easy to design, test and see how the process and the control system work together, and the whole integrated system can be studied and optimized simultaneously in detail.
The user has access to a set of predefined process component models that are conceptually analogous with concrete devices. The component libraries cover a comprehensive set of process and automation components such as pipes, valves, pumps, heat exchangers, tanks, measurements, controllers etc. One convenient feature in Apros is user component (UC) which can be utilized for creating own re-usable component structures. User component consists of basic Apros library components and possibly other user components. It can be easily re-used and shared with other Apros users.

In Apros, modelling is based on thermal hydraulics which is described using time-dependent conservation equations for mass, momentum and energy as well as correlations for friction and heat transfer (Technical Research Centre of Finland).

\section{Plant Model}

The reference plant is a commercial pulverized coalfired unit. The plant is rather new and it represents state of the art technology. It is used both in base load and cyclic operation mode. The once-through boiler of the plant is ultra-supercritical with live steam temperature of $600{ }^{\circ} \mathrm{C}$ and live steam pressure of $290 \mathrm{bar}$. The gross power capacity of the plant is $800 \mathrm{MW}$ and the net electric power is $750 \mathrm{MWe}$. The plant is also able to produce 90 MWth district heat for the surrounding region. The overview and scope of the plant model is illustrated in Figure 1. The following chapters introduce the plant model. The process is divided into three 
process sections and the control system comprises of seven sections.

The simulation model construction and validation can be divided into four steps. Firstly the model scope and boundary conditions are considered and decided based on the use of the model. Then the actual model is built up in the modelling environment. After model build-up the model is tuned to various steady state operating points and the model parameters are tuned by comparing the model responses and plant measurement data. Lastly the dynamic validation is performed by simulating transients that are compared to measurement data. Once these steps are completed successfully the model is ready to be used in different types of simulation experiments.

\subsection{Air and Fuel Feed}

Air and fuel feed section includes air supply lines, air preheaters, air flow control valves, raw coal supply line, coal mills and coal-air line to the furnace as it is presented in Figure 2.

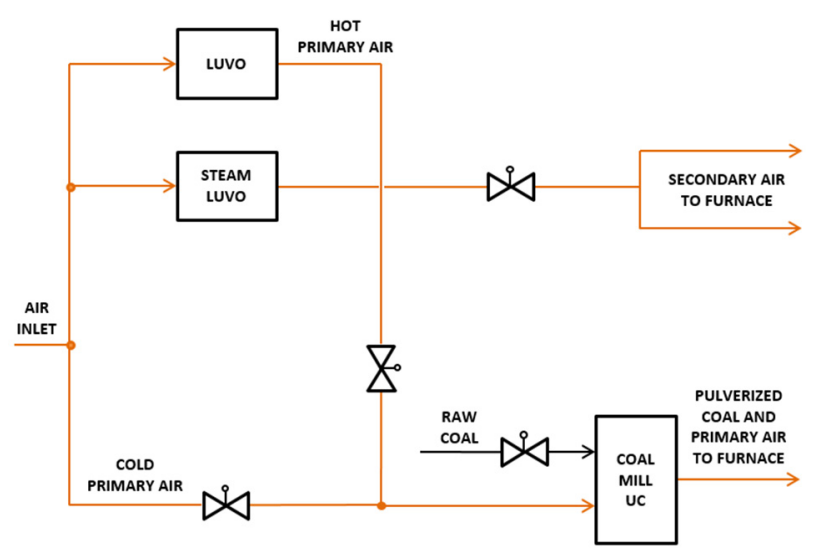

Figure 2. Air and fuel feed section model diagram.

In the model air is passed to the furnace in two phases, whereas in the real plant the number of air feed lines is larger. Primary air, which is fed through the coal mills, makes up about $30 \%$ of all combustion air. Primary air is a mixture of cold and preheated hot air. Hot air is preheated with flue gases in the air preheater, and cold and hot air are mixed at the inlet of the coal mill to control the coal mill outlet temperature. Secondary air makes up the major part of the combustion air, around $70 \%$. Secondary air is preheated with extraction steam and mixed with fuel-rich primary air in the furnace to give a proper air-fuel ratio.

The coal mills of the plant are modelled in detail using the user component feature of Apros. Coal mill model is an important part of cyclically operated pulverized coal-fired power plant simulator, and a valid mill model improves the accuracy of the plant's transient simulation. Load changes, start-ups and shutdowns can be simulated realistically if the dynamics of the mill model corresponds to dynamics of a real mill. The roll- type coal mill operation is as follows. Raw coal is dropped from the feeder belt into the mill where it lands on the grinding table and is pulverized by rollers. Primary air is used as carrier gas for grinded coal particles. Inside the mill primary air, which is blown from the bottom of the mill, dries the moist coal, picks up the pulverized coal particles from the grinding table and transports particles to the classifier section. Only the finest coal particles escape the mill through the classifier, whereas heavier particles fall back to the grinding table. By modifying the rotation speed of the classifier the amount of escaping coal powder can be controlled.

The proposed coal mill model was first introduced by (Niemczyk et al., 2012). The coal mill UC is tuned to simulate the behavior of the four mills of the real plant. The model is a so-called graybox-model based on physical knowledge and parameter identification methods. Primary air flow and raw coal flow including moisture are the inputs of the mill component. The output is the mixed air-coal flow which is passed to the furnace. In the coal mill model two particle sizes, raw and pulverized coal are considered, and the model comprises of equations for mass balances of raw and pulverized coal in different sections of the mill, overall energy balance and pressure losses inside the mill. In the model the coal storage inside the mill is divided into three different sections: raw and pulverized coal on the grinding table and pulverized coal in the air. The dynamic behavior of the coal storage inside the mill is crucial during load changes. A schematic representation of the mill model is presented in Figure 3. A more accurate description of the mill model is given in (Niemczyk et al., 2012; Kuronen, 2015).

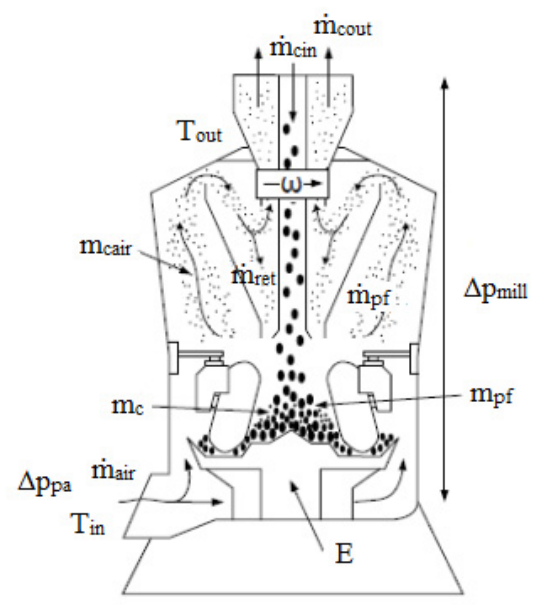

Figure 3. Schematic picture of a roll mill.

\subsection{Boiler}

The structure of the boiler model is illustrated in Figure 4. In the once-through boiler model the heat transfer between the combustion flames/flue gases and watersteam circuit is modelled by including all the real heat exchange surfaces into the model. These are 
economizers, evaporator, superheaters and reheaters. In the real plant the lower part of the evaporator comprises of spiral tube structure and the upper part is constructed with straight tubes. Hence in the model the evaporator is also divided into two separate parts with different dimensions and heat transfer properties. Heat transfer areas and pipe dimensions are fixed according to plant documentation. The heat transfer coefficients, radiation emissitivies and view factors of the heat exchange surfaces are adjusted empirically. Also the water separator, which separates water and steam before the superheating section, and water sprayers, which are utilized in controlling the temperature of the superheated steam, are modelled.

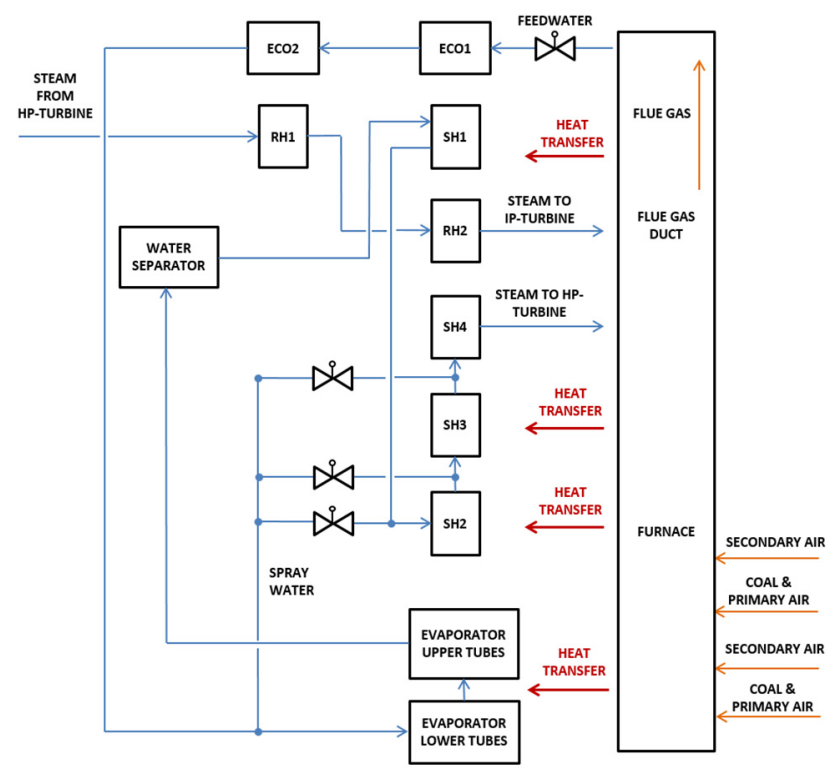

Figure 4. Boiler model diagram.

Flue gas section consists of the combustion chamber, burners and the flue gas duct. The dimensions of the combustion chamber and flue gas duct are equal to ones in the real plant.

\subsection{Turbine Plant}

Turbine plant model comprises of high-pressure (HP), intermediate-pressure (IP) and low-pressure (LP) turbines, steam extractions, turbine control valve and turbine shaft. Superheated steam flows from the final superheater to the HP-turbine through the turbine control valve, which is kept fully open, since the boiler is operated in sliding pressure mode. After the HPturbine steam is reheated in two phases in the boiler and brought to IP- and LP-turbines. The mechanical power produced by the turbines is transformed to electric power via shaft and generator components.

The turbine plant model scope does not include a condenser, where the expanded steam is passed after the LP-turbine, but the pressure after the last LP-turbine section is fixed according to the real conditions in the plant condenser. The scheme of the turbine plant model is shown in Figure 5. Turbine sections are composed of turbine components, which are connected to a turbine shaft. After each turbine section, part of the steam is extracted to be taken to the water preheaters and district heat exchangers. Since the feedwater and district heat sections are not included in the model, extraction flows are constantly controlled and the flows alternate according to the operating point. Hence the right mass balance is maintained. Extraction mass flows in different operating points have been collected from the plant's process and information system.

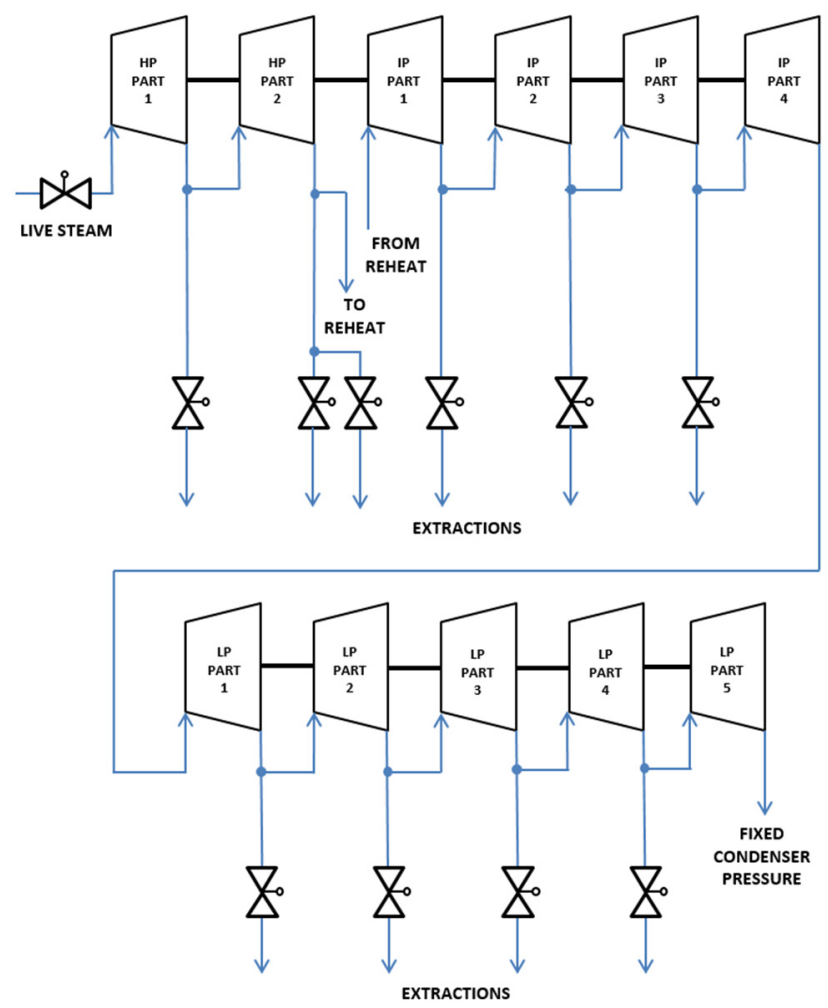

Figure 5. Turbine plant model diagram.

\subsection{Control loops}

All the main control loops of the plant are modelled and tuned in Apros. The advantage of Apros is that the process and control system can be modelled in the same simulation environment. The modelled control loops are:

- Block control

- Coal flow control

- Primary and secondary air control

- Live steam temperature control

- Reheated steam temperature control

- Feedwater control

- Extraction flow controls.

The co-ordination of turbine and boiler operation is realized by the block control (or unit control), which generates set point for the boiler and turbine to keep the desired load set point while maintaining the desired operating pressures and temperatures (Lamp et al., 2009). The user gives the gross power output set point 
via block control and all the other main controlled variables get their set points as a function of the power set point. The user given set point signal is corrected with a power correction controller according to the deviation between the power set point and measured generator power. The block control diagram is presented in Figure 6.

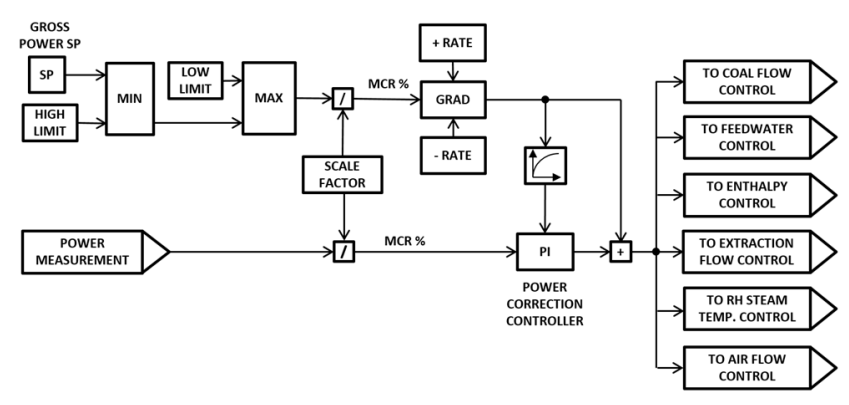

Figure 6. Block control diagram.

The coal flow set point is determined as a function of plant load and it is then adjusted with a heat value correction which takes into consideration the changing content of the raw coal. The coal composition depends on the type of the coal and plants utilize coals from different sources. The changing composition affects strongly on the coal flow control which is based on a function between plant load and coal mass flow. Heat value correction is based on the enthalpy difference between water at the inlet of the boiler and steam at the outlet of the boiler. Designed enthalpy difference is compared with measured one and the coal heat value in the control loop is corrected according to the enthalpy deviation.

The amount of primary air is controlled according to plant load level and coal flow. The mass flow of primary air is approximately two times bigger than coal mass flow. The temperature of the air-coal mixture at the outlet of the mill is controlled with the ratio of preheated and cold primary air. Secondary air flow is adjusted according to the total air demand, which is a function of the power level and coal flow set point. Secondary air set point is modified with $\mathrm{O}_{2}$-control (oxygen-control), which adjusts the volume of oxygen in the flue gas to the desired level. Secondary air, primary air and coal mill temperature control loops are pieced together in air control diagram.

The live steam temperature is controlled by spraying saturated water among the live steam in three phases. Live steam temperature set point after the last superheater is kept constant in the model. For the first two attemperators the temperature set point is defined by the temperature difference across the attemperator. Reheated steam temperature is controlled correspondingly.

The feedwater control loop is presented in Figure 7. The set point for the feedwater flow is determined according to the load level and it is modified with enthalpy correction. Enthalpy correction factor is calculated according to deviation between the design and measured steam enthalpy after the evaporator. Since steam enthalpy is a function of temperature and pressure, enthalpy correction controls steam temperature and pressure after the evaporator section. Feedwater flow is adjusted with a control valve.

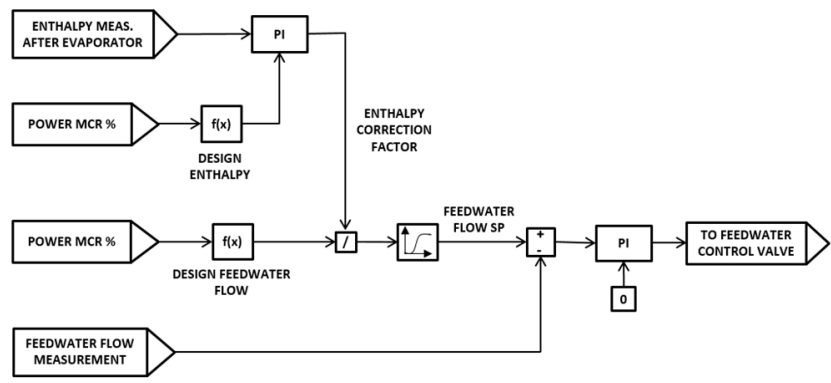

Figure 7. Feedwater control diagram.

Although feedwater preheaters, -tank, -pumps and condenser are not included in the model the extraction flows from the turbines are modelled to achieve the correct mass balance in the water-steam cycle. Extraction flow controls consist of multiple individual valve controls, and set points for the flows are set as a function of plant load level.

\section{Model Validation and Simulation Results}

The plant model was first validated in multiple steady state conditions between the gross power range of 50$100 \%$. When the steady state validation results showed good agreement the model was validated dynamically by simulating load changes that are typically performed during grid load compensation. The dynamic validation was done between the gross power range of 87-100\%. The dynamic validation results are presented in this section.

The gross power output is presented in Figure 8. The model response (red line) follows fairly well the measurement curve (blue line), but it does not overshoot or undershoot the set point curve (green line) as strongly as the measurement curve. The deviation between the curves is a consequence of multiple factors, since the inaccuracies of the whole model culminate on the power output response. Real controller tuning parameters and load-dependent set point functions of main variables were not known during the modelling, and it reflects as a deviation between the model and plant responses during load change transients. The high-frequency oscillation in the power curve as well as in feedwater curve is caused by measuring errors and backlash of valves. This type of oscillation is not needed to be included in the model. 


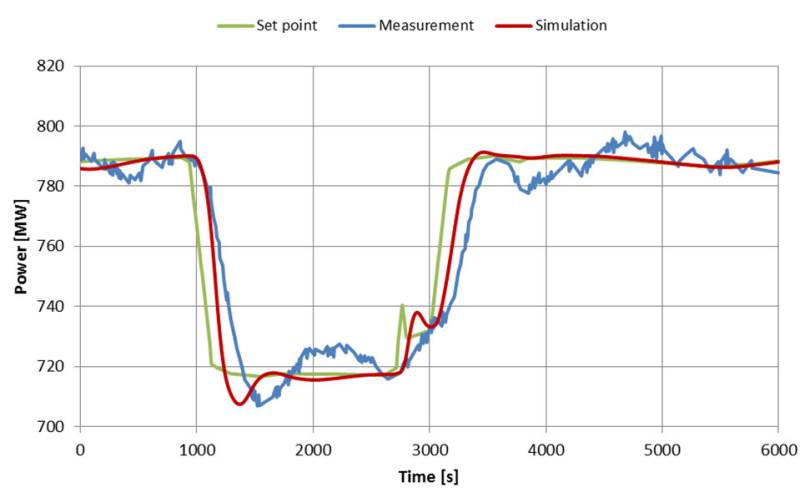

Figure 8. Gross power output.

The raw coal mass flow from the feeder to the coal mill is showed in Figure 9. Dynamically the raw coal flows are quite similar. There are notable peaks in the measured coal flow curve when the load changes are made. The model is able to reproduce the peak when the load is decreased, but there are slight difference between the curves, when the load is increased back to the original level. This originates from the more aggressive controller tuning at the plant. Also the coal flow controller is probably a bit more advanced in the plant control system, whereas in the model an ordinary PIcontroller is used. The raw coal flow level is also a bit higher in the model, around $1 \mathrm{~kg} / \mathrm{s}$, depending on the operating point. The reason for this can be found from the load-dependent set point function which is a compromise among other variable set point functions. Differences in the coal flow reflect directly on the power output.

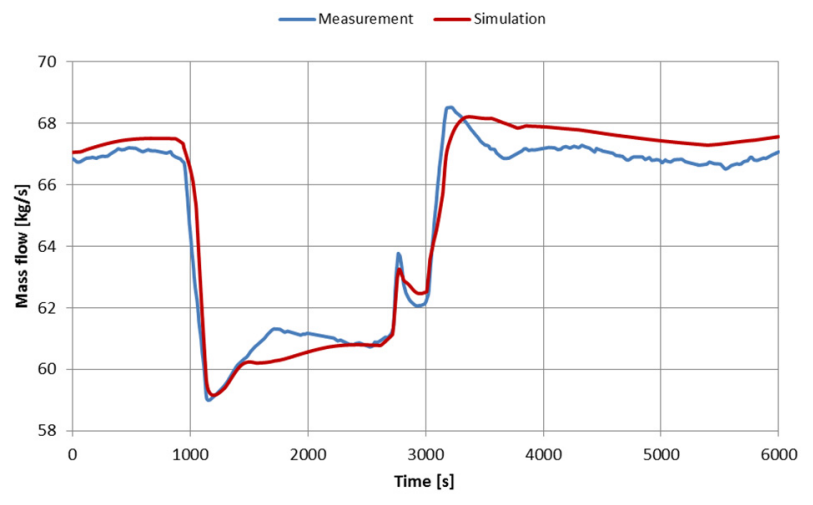

Figure 9. Raw coal mass flow into the coal mill.

The feedwater flow is presented in Figure 10. The simulated feedwater mass flow level is around two percent lower than the measured level. Once again the main reason is the load-dependent set point function which is most probably not the same one that is set in the plant control system. Also the absence of HP- and LP-preheaters, condenser, feedwater tank and the simplified extraction flow modelling have an impact on the feedwater flow in the model. However the curves are dynamically uniform if the high-frequency oscillation is not considered.

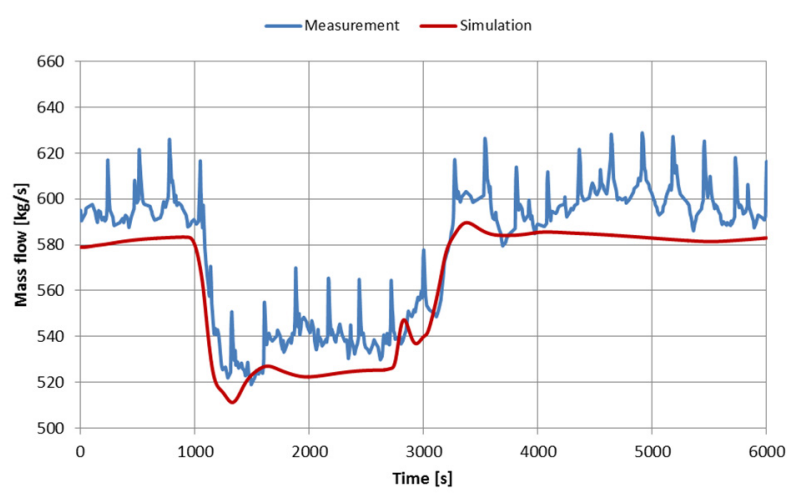

Figure 10. Feedwater mass flow.

The simulated total air mass flow is fairly well in line with the measurement as can be seen from Figure 11. Air controllers at the plant and in the model seem to be tuned quite similarly since the total air mass curves are rather close to each other under the load changes.

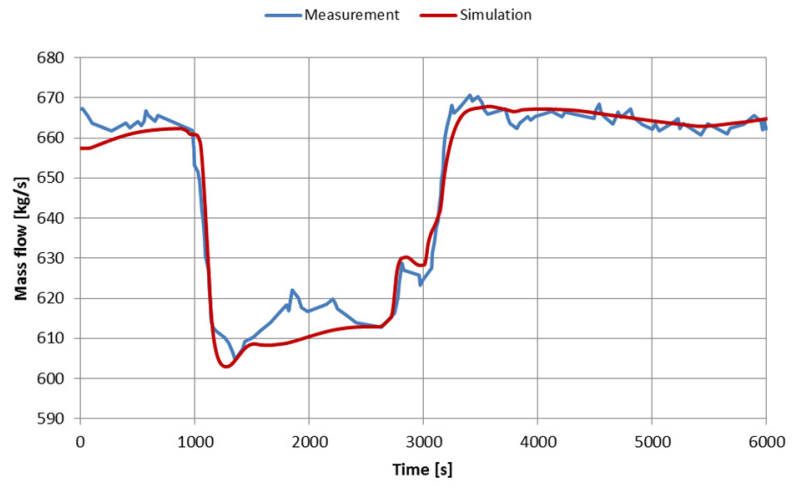

Figure 11. Total air mass flow.

Measured and simulated live steam temperatures after the final superheater are illustrated in Figure 12. The simulated temperature corresponds to the measurement, although the exact same dynamic behavior is difficult to achieve. The correspondence between the live steam temperatures indicates that the dimensions of the heat exchange surfaces and heat transfer coefficients in the boiler are substantially correct. Also the live steam temperature control maintains the temperature close to the set point $\left(597^{\circ} \mathrm{C}\right)$ during the load changes.

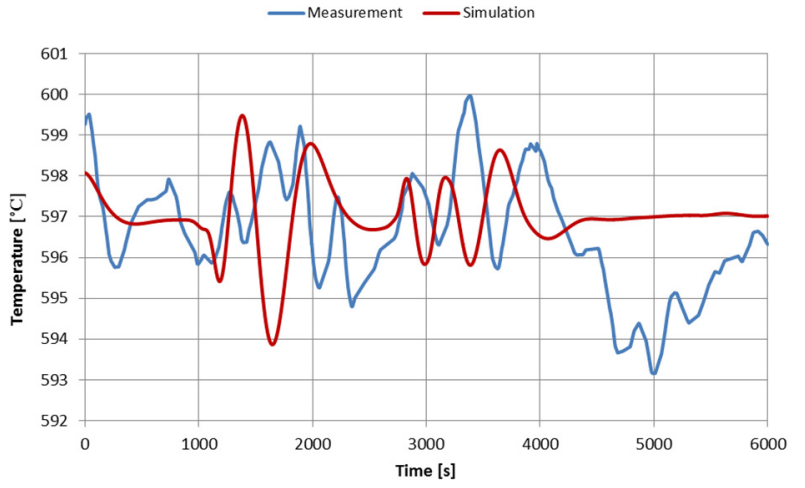

Figure 12. Live steam temperature. 


\section{Conclusions}

Pulverized coal-fired power plants are increasingly participating in electric grid load control due to expanded intermittent renewable power generation. This sets new challenges related to flexibility and controllability of the coal plants since the plants are operated cyclically to maintain a steady load in the electric grid. For example process- and control strategy changes are often needed in base load plants which are not designed to be operated cyclically. New solutions can be designed and tested with time-variant dynamic simulation models.

This paper presented a dynamic simulation model of a full-scale commercial pulverized coal-fired power plant. The model was constructed and simulated in dynamic simulation software Apros. The model included the main processes and control loops of the real plant, but some considered simplifications were done to delimit the scope of the model. The model was validated both on steady-state and dynamic conditions. Based on the dynamic validation results, which were illustrated in this paper, the model responses corresponded fairly well to the plant measurements between the power range 87$100 \%$. Even if the model is a simplified version of the real plant, it can be already utilized e.g. for design and testing purposes.

In future the plant model can be developed in various ways. Firstly new subprocesses and control loops could be added to the model. Secondly re-tuning the control loops, defining appropriate time constants and loaddependent set point functions would increase the model accuracy. Thirdly a more comprehensive model validation on a broader power range should be performed, so that the model could be reliably simulated on the plant's whole operating range.

\section{References}

U. Krüger, M. Rech, S. Tuuri. H. Zindler, Dynamischer Kraftwerkssimulator zur leittechnischen Optimierung der Sekundärantwort des E.ON-Kraftwerks Wilhelmshaven, Kraftwerkstechnik 2015 - Strategien, Anlagentechnik und Betrieb, Technische Universität Dresden, pages 641-649, 2015.

J. Kuronen, Improving Transient Simulation of Pulverized Coal-Fired Power Plants in Dynamic Simulation Software, Master's Thesis, Tampere University of Technology, 88 p, 2016.

B. Lamp, K. Wendelberger, B. Meerbeck, A New Era in Power Plant Control Performance, Siemens, Reprint from COAL POWER Magazine, 6 p, 2009.

P. Niemczyk, P. Andersen, J. D. Bendtsen, T. Sondergaard Pedersen, A. P. Ravn, Derivation and Validation of a Coal Mill Model for Control, Control Engineering Practice, 20(5): 519-530, 2012.

M. Richter, F. Möllenbruck, A. Starinski, G. Oeljeklaus, K. Görner, Flexibilization of Coal-Fired Power Plants by
Dynamic Simulation, In Proceedings of the $11^{\text {th }}$ International Modelica Conference, pages 715-723, 2015.

R. Starkloff, F. Alobaid, K. Karner, B. Epple, M. Schmitz, F. Boehm, Development and Validation of a Dynamic Simulation Model for a Large Coal-Fired Power Plant, Applied Thermal Engineering, 91: 496-506, Elsevier, 2015.

Technical Research Centre of Finland, Apros Thermal Hydraulics, Thermal Hydraulic Flow Models, Available: http://www.apros.fi/filebank/71-

Apros_thermal_hydraulics_-_general.pdf. 